\title{
New Methods for Determination of Interstitial Liquid Levels in Hanford Waste Tanks
}

\author{
D. A. Barnes
}

Date Published

January 1995

To Be Presented at

Waste Management 1995

Tucson, Arizona

February 26 - March 2, 1995

To Be Published in

National Conference, Multiple Sponsor

Prepared for the U.S. Department of Energy

Office of Environmental Restoration and

Waste Management
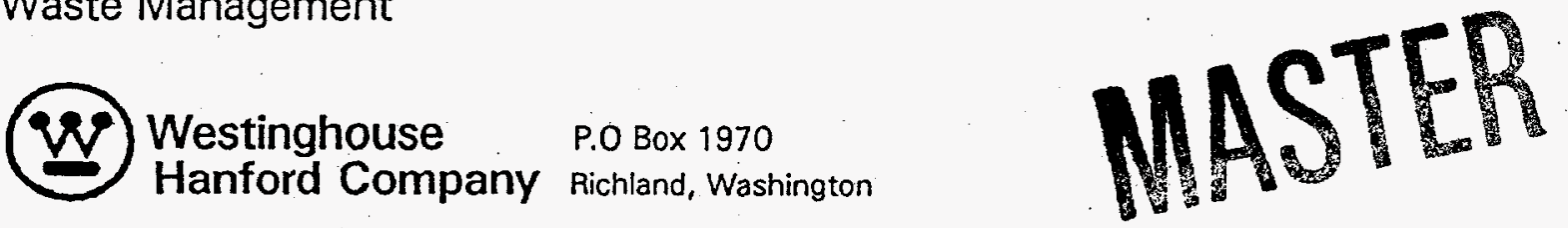

Hanford Operations and Engineering Contractor for the

U.S. Department of Energy under Contract DE-AC06-87RL10930

Copyright License By acceptance of this article, the publisher and/or recipient acksowledges the
U.S. Government's right to retain a nonexclusive, royalty-free license in and to any copyright covering this paper.

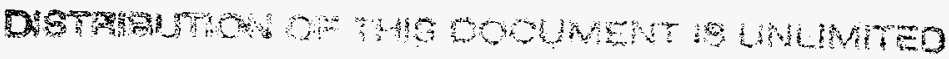




\section{LEGAL DISCLAIMER}

This report was prepared as an account of work sponsored by an agency of the United States Government. Neither the United States Government nor any agency thereof, nor any of their employees, nor any of their contractors, subcontractors or their employees, makes any warranty, express or implied, or assumes any legal liability or responsibility for the accuracy, completeness, or any third party's use or the results of such use of any intormation, apparatus, product, or process disclosed, or represents that its use would not infringe privately owned rights. Reference herein to any specitic commercial product, process, or service by trade name, trademark, manufacturer, or otherwise, does not necessarily constitute or imply its endorsement, recommendation, or favoring by the United States Government or any agency thereof or its contractors or subcontractors. The views and opinions of authors expressed herein do not necessarily state or reflect those of the United States Government or any agency thereot.

This report has been reproduced from the best available copy.

Frinted in the United States of America

DISCLM-2.CHP (1-91) 


\section{DISCLAIMER}

Portions of this document may be illegible in electronic image products. Images are produced from the best available original document. 


\title{
NEW METHODS FOR DETERMINATION OF INTERSTITIAL LIQUID LEVELS IN HANFORD WASTE TANKS
}

\author{
Author - David A. Barnes, Principal Engineer, Westinghouse Hanford Co. \\ Co-author - Rick E. Raymond, Manager, Plant Engineering, Westinghouse Hanford Co. \\ Co-author - Paul D. Whitney, Senior Research Scientist, Pacific Northwest Labs
}

\begin{abstract}
The key to the leak detection program for many tanks at Hanford is the method used to evaluate the apparent interstitial liquid interface (ILL) within the pore space of the solid waste medium (either crystalline or sludge). Three new approaches were introduced in the summer of 1993 (count rate, derivative, and sigmoid), all of which significantly improved the accuracy and repeatability of interstitial liquid level values from neutron survey data. This paper summarizes the three new methods and details a case study in which, as a direct result of this improved analysis, a tank that had been declared an "assumed leaker" was reclassified as "sound" for the first time in Hanford's 50 year history.
\end{abstract}

\section{INTRODUCTION}

Many of the 177 underground nuclear waste storage tanks at Hanford do not have liquid waste surfaces, and potential leakage must be evaluated by determining the Interstitial Liquid Level (ILL). The in-tank photograph shown in Figure 1 indicates why a surface level measurement alone cannot be used as a valid leak detection indicator in many tanks. Since 1985, a total of 61 liquid observation wells (LOWs) have been installed for the purpose of leak detection, with additional installations continuing. A LOW is a hollow tube made of fiberglass, steel, or

"TEFZEL ${ }^{\circledR 1 "}$ (Registered trademark of DuPont), which is capped at the bottom, and inserted into the waste to a point near the bottom of the tank. The interior of this tube can be opened to the atmosphere via surface risers, but is isolated from the waste, thus providing a surveying environment which is free from direct contamination (as shown in Figure 2). These LOWs are surveyed weekly, using wireline logging techniques common to the geophysical and petroleum industries. Both thermal neutron and gross gamma ray probes are used, but the neutron probe normally provides higher quality data. The resulting surveys, (plots of depth vs. count rate), are then evaluated using interpretation software to determine the exact depth of the liquid interface. Plotting the derived liquid interface against time can document trends and changes in liquid levels. These interface changes, when analyzed with statistical methods, provide the basis for an effective leak detection program.

As mentioned above, the two probes most commonly used for this analysis are the thermal neutron probe and the gross gamma probe. The gross gamma probe at Hanford consists of a single Geiger-Mueller detector and its associated electronics, which acts very much like a pointsource detector. Since the waste in Hanford's single -shell tanks was generated from 25 to 50 years ago, any short-lived isotopes have long since decayed, and are present only at insignificant levels. The primary gamma-producing isotope that remains is $\mathrm{Cs}_{\mathbf{1 3 7}}$, which is in a highly water-soluble form in most cases. Although this solubility normally results in a clearly identifiable change in gamma activity at the liquid interface, the change in count rate is not normally as definitive as that provided by the neutron probe. In most cases, the gamma profiles are less sensitive to changes in fluid saturation, and are normally used to support and verify the primary neutron data. The remainder of this paper will focus on a new and more detailed analysis of the neutron count profiles.

The underlying physical principle behind a thermal neutron probe is its response to moisture, more specifically, to the hydrogen associated with water. The neutron source, located near the bottom of the probe, consists of 1.5 Curies of americium/beryllium (AmBe), which emits "fast" (high-energy) neutrons at approximately $4.5 \mathrm{MeV}$. Two of the most common neutron detectors are made from either helium $3\left(\mathrm{He}_{3}\right)$ or boron trifluoride $\left(\mathrm{BF}_{3}\right)$, both of which are gasses and emit an alpha particle when a thermal neutron is absorbed. The initial energy level of the source 
neutrons, however, is much too high to allow capture by either detector. The neutrons must achieve a significantly lower energy level before they can be detected. It is the rate of this neutron "thermalization" process that is of primary interest.

One of the most effective fast neutron moderators known is hydrogen, primarily because its mass is virtually equal to that of a neutron. In a high-hydrogen environment a fast neutron will slow to thermal energies nearer the source, and will thus be captured by a detector (yielding high count rates). In virtually all other environments, the neutrons will maintain their initial energy levels far longer (i.e., yielding lower count rates at the detector). Since high hydrogen densities are normally associated with liquid water (or organics in some cases), this makes the thermal neutron probe a very sensitive moisture detector. In practice, the $\mathrm{BF}_{3}$ detector is used at Hanford instead of the $\mathrm{He}_{3}$ detector because of its superior level of discrimination in high-gamma environments. A typical neutron probe response across a liquid/solid or liquid/vapor interface goes from high counts in the liquid phase to low counts in the solid or vapor phase, and normally exhibits an "S", or sigmoid-shaped response curve (unless modified by nearby porosity and saturation changes).

\section{BACKGROUND}

The initial LOW survey program was formally established in 1985, along with basic software to determine the liquid interface from neutron and gamma scans. This interpretation software was designed primarily for ease of use, and was expected to yield only rough approximations of liquid levels. The major elements of this original analysis are summarized below followed by the resulting limitation.

- The data was collected only at intervals of 0.1 foot (1.2 inches), and the results were also recorded in these increments. No interpolation between data points was attempted. Limitation: interpolation could have improved resolution.

- The computed liquid interface was obtained by visually setting crosshairs on a monitor screen. Limitation: graphical resolution was poor and the depth scale was not expanded adequately, leading to potentially large errors in depth.

- Results often could not be repeated, even by the same technician. Limitation: increased data scatter, particularly when different technicians were used.

- If there was no significant visible difference between the established baseline plot (taken several years earlier) and the current scan, the difference was recorded as "zero", and no quantitative analysis was attempted. Limitation: the difference was often significant, although barely visible on the compressed graphic scale then in use.

- A flaw in the software allowed the interface to be established at a data point which was not on the recorded data curve. Limitation: data could be offset by as much as 1 to 2 inches.

- Analysis of the "top of tank" marker was not attempted. Limitation: Without a fixed internal depth reference all systematic errors in the van depth system translated directly into ILL calculation errors.

- Baseline values used for leak detection (both surface level and ILL data) were fixed single values. Most of these values had been set several years earlier. Limitation: If natural evaporation, condensation or settling is occuring the baseline should change with time at a relatively constant slope. In the past, this inflexible approach led to some naturally evaporating tanks being declared "assumed leakers" when fixed and outdated limits were exceeded.

Since tolerances were large, however, this method was considered acceptable for many years. Over time it simply became the "standard", and the limitations of this approach were not questioned or re-evaluated. Most tanks were stable enough so that this method was adequate for gross leak determinations.

The primary focus of this paper is waste tank SX-102. This is a single-shell tank constructed in 1954 which began receiving waste as soon as it was completed. The tank exhibits a relatively thin solid crust (approximately 1.0"-1.5" thick, most likely floating on liquid), and the liquid observation well (LOW) data is the official means of leak detection. Although a surface level 
conductivity device is operable, it has been in the "intrusion mode" for several years, with only occasional surface level measurements taken (figure 3).

In the summer of 1993 the ILL on SX-102, as determined by LOW neutron surveys, exhibited a sharp decrease (based on the established evaluation technique at the time), ultimately exceeding the decrease criteria set for leak detection. As shown in Figure 4, the data indicates a relatively constant level for several years (with a few notable variations) followed by a sharp decrease. The apparent sudden decrease follows a classic leak profile, and as a result of this profile and the official leak detection criteria being exceeded, the tank was declared an "assumed leaker". Preparations for emergency pumping of this tank were initiated, which is a very expensive and manpower-intensive operation. Tank SX-102 was on the "Hydrogen Watch List", a safety classification which requires a special safety analysis and associated precautions prior to allowing work in or around the tank.

\section{CURRENT METHODOLOGY}

The apparent leakage of SX-102 prompted a fresh look at the ILL interpretation techniques in use at the time. It soon became apparent that a significant amount of error could be generated (as outlined in the "Background" section), and that a much more accurate analysis was technically feasible. One of the most damaging past practices was that of calling the change in level "zero" if no separation was clearly visible between the baseline plot and the current survey. (Some of these apparent "zero changes" resulted from the poor graphic presentation available.) It was this practice that generated most of the flat portion of the ILL plot prior to the sharp decline. Once the decline became large enough to be identified, the rate of decrease was magnified as a result of the other systematic errors in the interpretation technique, as previously discussed.

As a direct result of identifying the limitations of the existing system, three new analysis techniques were developed. The methods are summarized below, followed by a corrected interpretation of the SX-102 ILL data.

Determination of the exact depth of the liquid interface currently involves three distinct analysis techniques. All three approaches (count rate, derivative, and sigmoid) have been applied to each tank, and the technique indicating the most consistent, stable and repeatable results has been chosen as the "official" method for that tank. Fortunately, the historical database of raw survey data extends back to 1985, and a thorough evaluation is possible to determine the most applicable method.

An important part of all three new approaches is analyzing the "top marker". This feature is identified by the sharp increase in counts at the interface between the tank vapor space and the cement structure of the dome. Figure 2 illustrates this feature for SX-102. Since this feature cannot move it is used as an internal depth calibration. Where this feature is sharp and welldefined (typically in 4 inch risers) the software shifts all of the raw data by the amount required to place the top marker exactly on depth. The resulting ILL values exhibit far less data scatter, since most depth problems associated with the LOW survey van have been removed. Where the LOW has been installed in a riser larger than 4 inches (up to 12 inches) the sharpness of this feature degrades, and cannot be used reliably in about one-third of the tanks.

Most neutron survey data generates acceptable results with all three approaches, but difficult analytical situations occasionally occur. In some tanks, one or two of the available methods fail for various reasons. The profile of every tank, however, has been successfully analyzed using at least one of the three approaches outlined below.

\section{The Count Rate Method}

The first method is known as the "count rate method". This simplistic but accurate approach relies on taking an average count rate immediately below the expected interface $(100 \%$ liquid saturated) and an average count rate immediately above the expected interface $(<100 \%$ 
saturated) across a pre-determined depth "window". The two values are then averaged, and the depth corresponding to this "average" count rate is designated as the ILL depth. In practice, this is an iterative process, with the initial "estimate" of the liquid interface being the extrapolated current baseline for the tank, which represents the best guess at the expected depth on the survey date. (Remember that a sloped baseline is used, and the "expected" ILL varies with time.) An "offset" is then assigned above and below that depth to establish a "count rate window" on either side of the expected interface. The resulting windows are intended to represent the stable counts above and below the expected interface. Total count rates are taken in both of these windows, to provide a liquid-filled count rate below the interface and a partially-saturated count rate above the interface. A midpoint count rate is determined by averaging the two and comparing the result with the initial depth estimate. If the two depth values do not match within the convergence criteria, then the newly-determined value is used as a starting estimate and the process is repeated until the values converge. Deviation from the expected baseline is then computed and presented as part of the quality control and data reporting process. (A typical count rate interpretation is shown in Figure 5.)

\section{The Derivative Method}

In the derivative method, a "depth window" is established which symmetrically covers both sides of the feature to be evaluated. This is the only method which is not iterative, and does not tie the initial guess to the baseline extrapolation. Within this window, the raw survey data (taken at 0.1 foot increments) is smoothed using a cubic spline function; this function is then broken into equal 0.01 foot increments to improve depth resolution. The resulting output function has a smooth and continuous first and second derivative. (This is one of the inherent mathematical characteristics of a cubic spline curve fit.) The derivative of this function is then calculated every 0.01 feet, and the liquid interface is defined as either the minimum or maximum value of the derivative (depending on slope). This method defines the liquid interface as the exact point (within 0.01 feet) of maximum slope (maximum rate of change). In most cases, the derivative method yields a slightly different absolute value than the count rate technique, but both methods are comparable, and the long-term data trends do not differ significantly. The derivative method is illustrated in Figure 6.

\section{The Sigmoid Method}

Any time raw data follows a predictable pattern, it can be evaluated by curve fitting to a mathematical function of similar shape. In most cases, this mathematical function will behave more consistently and will exhibit less scatter than the original raw data. This approach was applied to the classic " $\mathrm{S}$ " shaped response of a neutron probe measuring a liquid interface. Equation 1 is the exponential function used to simulate this response.

$$
\text { Count Rate }=\frac{a}{1+e^{-c(x-b)}}+d \quad \text { Equation (1) }
$$

where $\quad a=$ Count rate range (maximum - minimum)

$b=$ Function midpoint (symmetrical around $b$ )

$c=$ Shape factor (ranging from gradual to abrupt)

$d=$ Minimum count rate (exponential limit)

$x=$ Depth evaluated

Virtually any sigmoid shape can be fit to this function by appropriate adjustment of the variables $a, b, c$, and d. In practice, a non-linear optimization routine is used to adjust the values of these four variables in order to maximize the regression coefficient $\left(R^{2}\right)$ between the raw data and the resulting curve-fit function. Once the best possible fit is achieved, the midpoint $b$ (point of symmetry) is defined as the liquid interface, (as illustrated in Figure 7). As with the count rate method, the resulting answer is fed back into the equation as a starting value, and the routine iterates to convergence. In approximately $50 \%$ of the tanks, the sigmoid method proved noticeably superior to the other two methods. 


\section{Determịning the Best Method}

To determine the best method, each tank is analyzed by all three methods, with all historical data being re-evaluated. The resulting outputs are plots of the liquid interface (level) vs. time. From these plots, the analyst can determine increasing and decreasing linear trends, as well as the standard deviation of the data points about the trend line. The most appropriate method is the one which produces the tightest data cluster about the linear trend line (minimum standard deviation), while also providing the fewest number of data analysis failures. (The most common problem is a "failure to converge".)

Variations from baseline greater than 2 standard deviations are considered "suspect", and the surveys are repeated. Repeatable variations greater than $+/-3$ standard deviations are considered legitimate anomalies, and are reported as potential leaks or intrusions. Once the optimum method and analysis parameters are chosen for a tank, they are stored in the central computer control file, ensuring that the analyses for all past and future surveys will be made on a comparable basis.

\section{CASE STUDY, TANK SX-102 LEAK DETERMINATION}

In May of 1993, waste tank SX-102 appeared to experience a sudden downturn in the interstitial liquid level (ILL), primarily due to the poor resolution of the existing analysis technique (as previously discussed). Because of the apparent sudden decrease in ILL, the tank was declared an "assumed leaker", and preparations were being made to perform an "emergency pumping" of the tank. During these preparations, the data was re-analyzed using the techniques just described, and a steady, long-term decreasing trend became apparent, with no major changes in slope. Although the new analysis techniques were in their infancy at the time, they proved conclusively that the decrease in liquid level was due to evaporation, which had been taking place for at least nine years. This was the first time a sloping baseline (taking into account natural evaporation and/or condensation trends) had been applied to raw tank data. A psychrometric study of the apparent evaporation trend was commissioned, resulting in a calculated evaporation rate which very closely matched the new ILL interpretation shown in Figure 8 . The study included physical, thermal, and hydraulic modeling, and yielded a best estimate of evaporation rate equal to 0.68 inches/year, The linear correllation of ILL data provided a slope of approximately 0.63 inches/year. These numbers match within the expected errors of the two methods used. As a result of this new interpretation, the tank was recategorized as "sound", and a multi-million dollar emergency pumping operation was avoided. 
Figure 1 - Typical Solid Waste Surface with LOW Installed

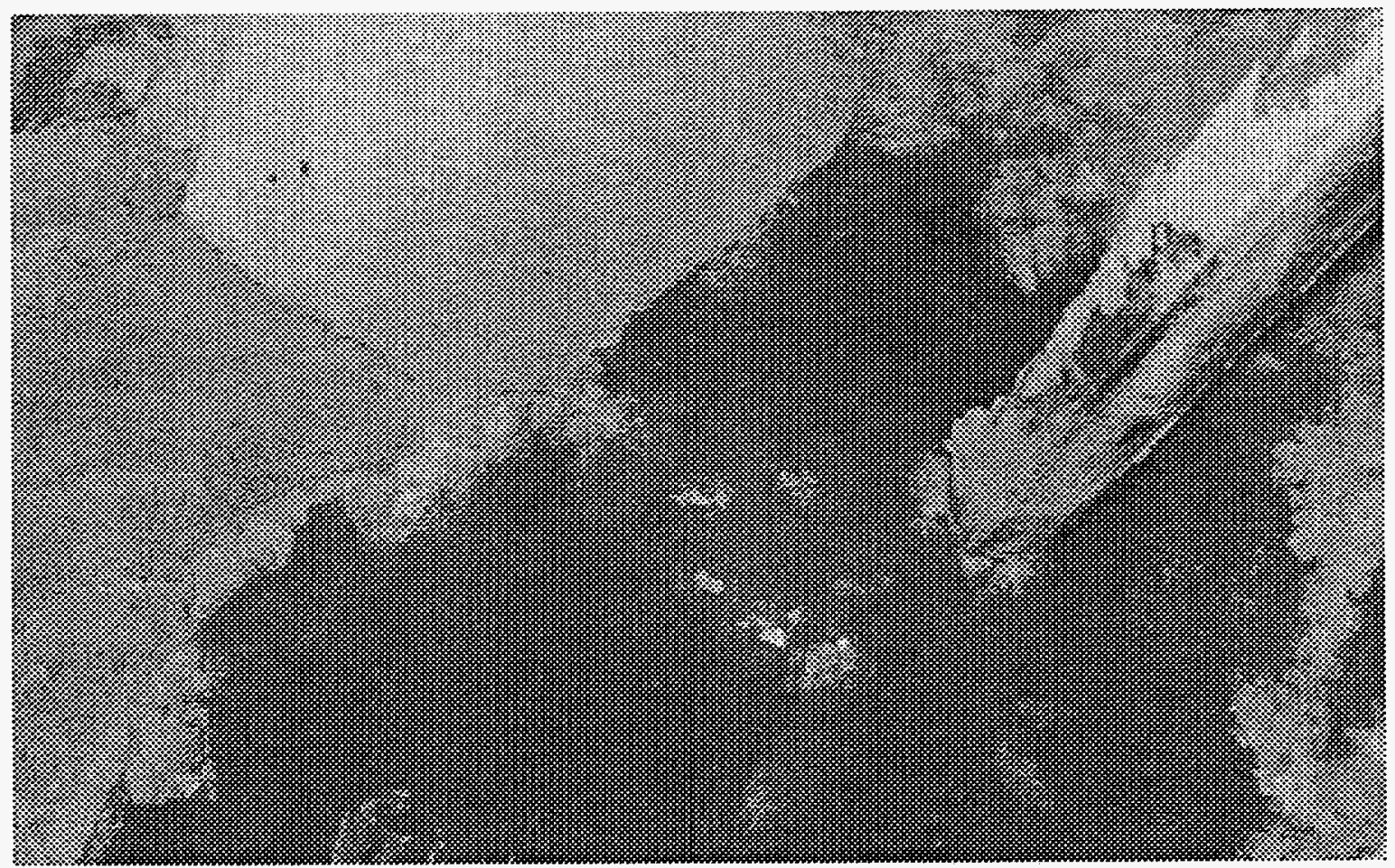

Figure 2 - LOW Schematic \& Typical Neutron Profile

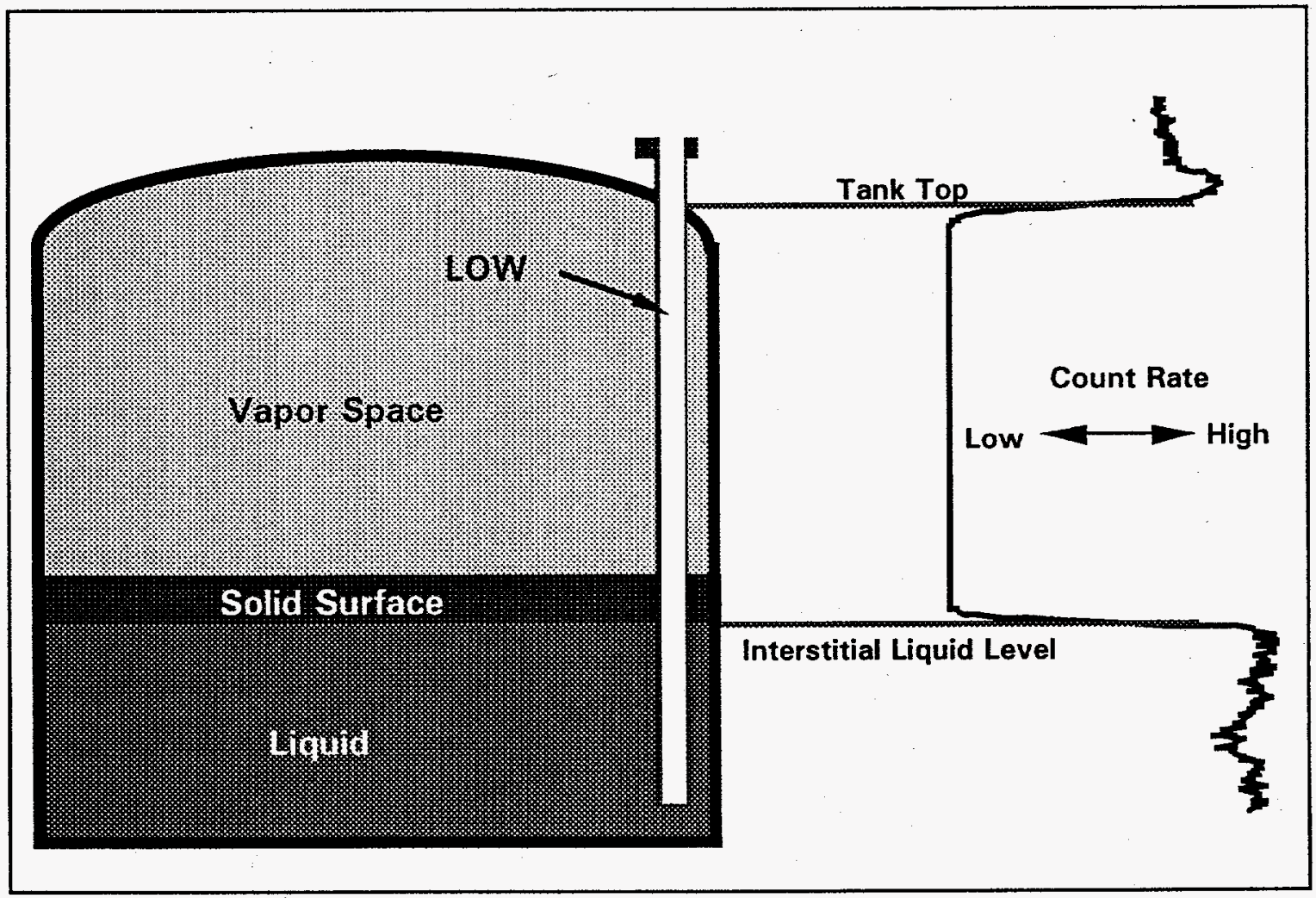


Figure 3: Tank SX-102

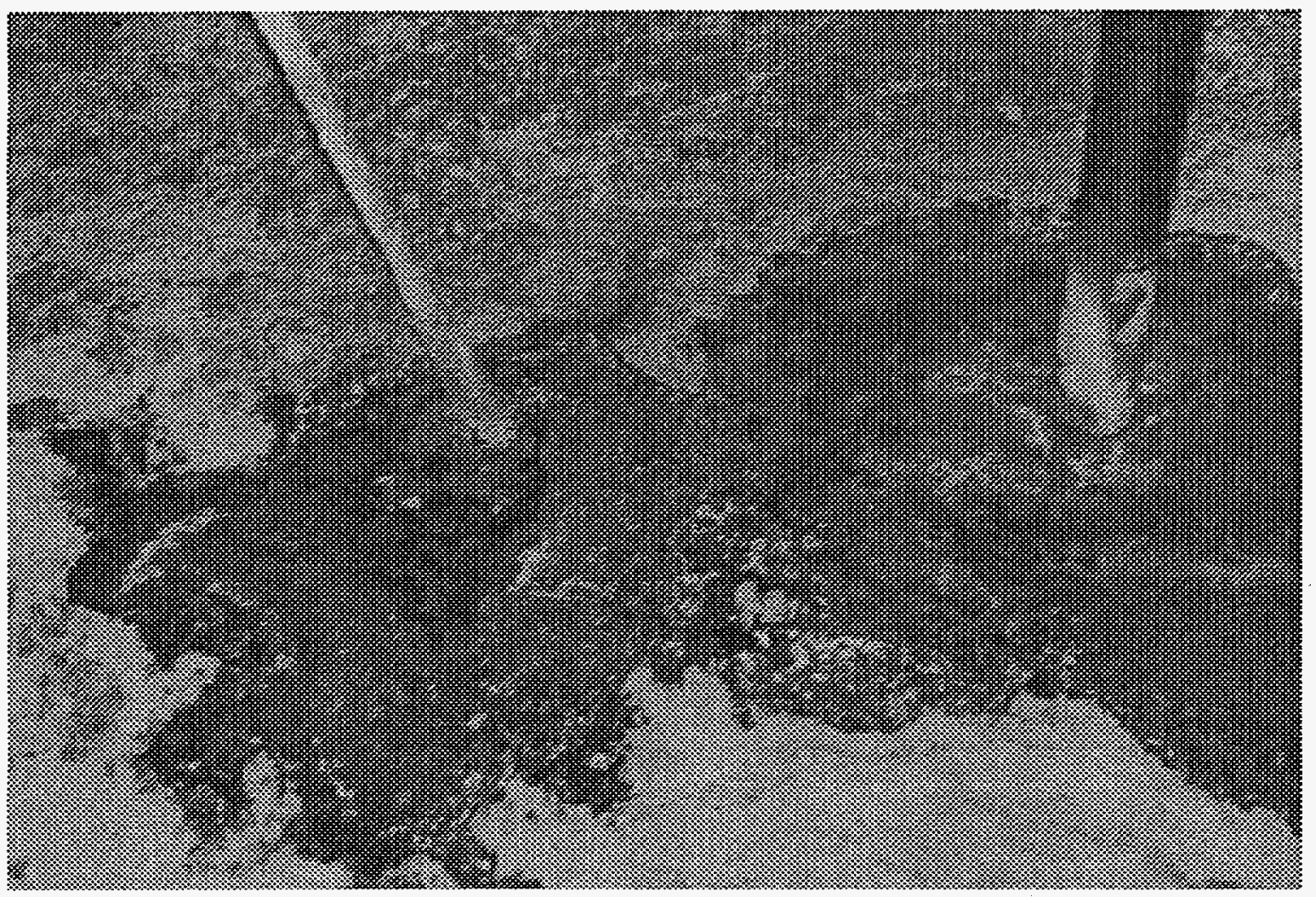

Figure 4 - SX-102 Original ILL Analysis -

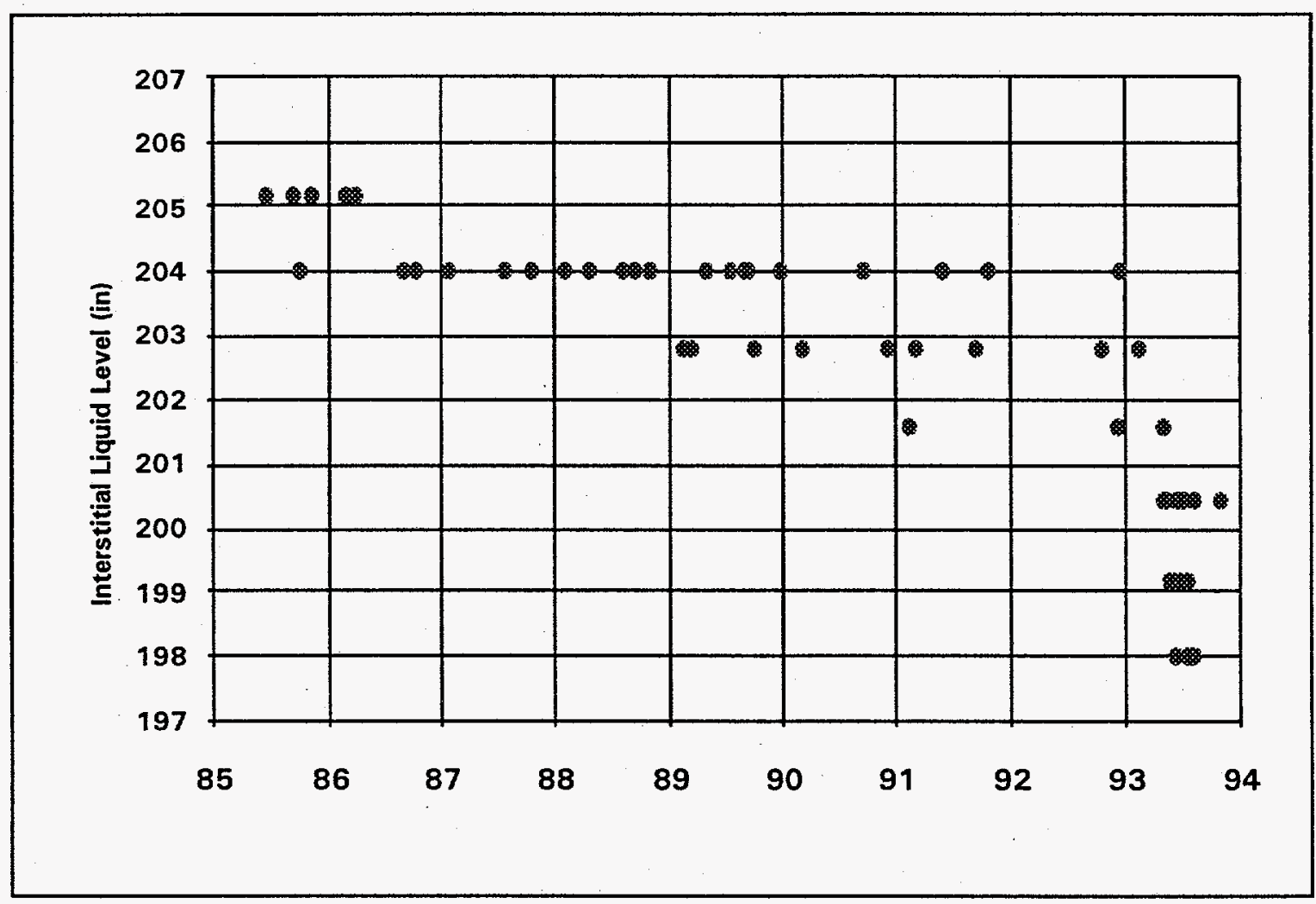


Figure 5 - The Count Rate/Midpoint Method

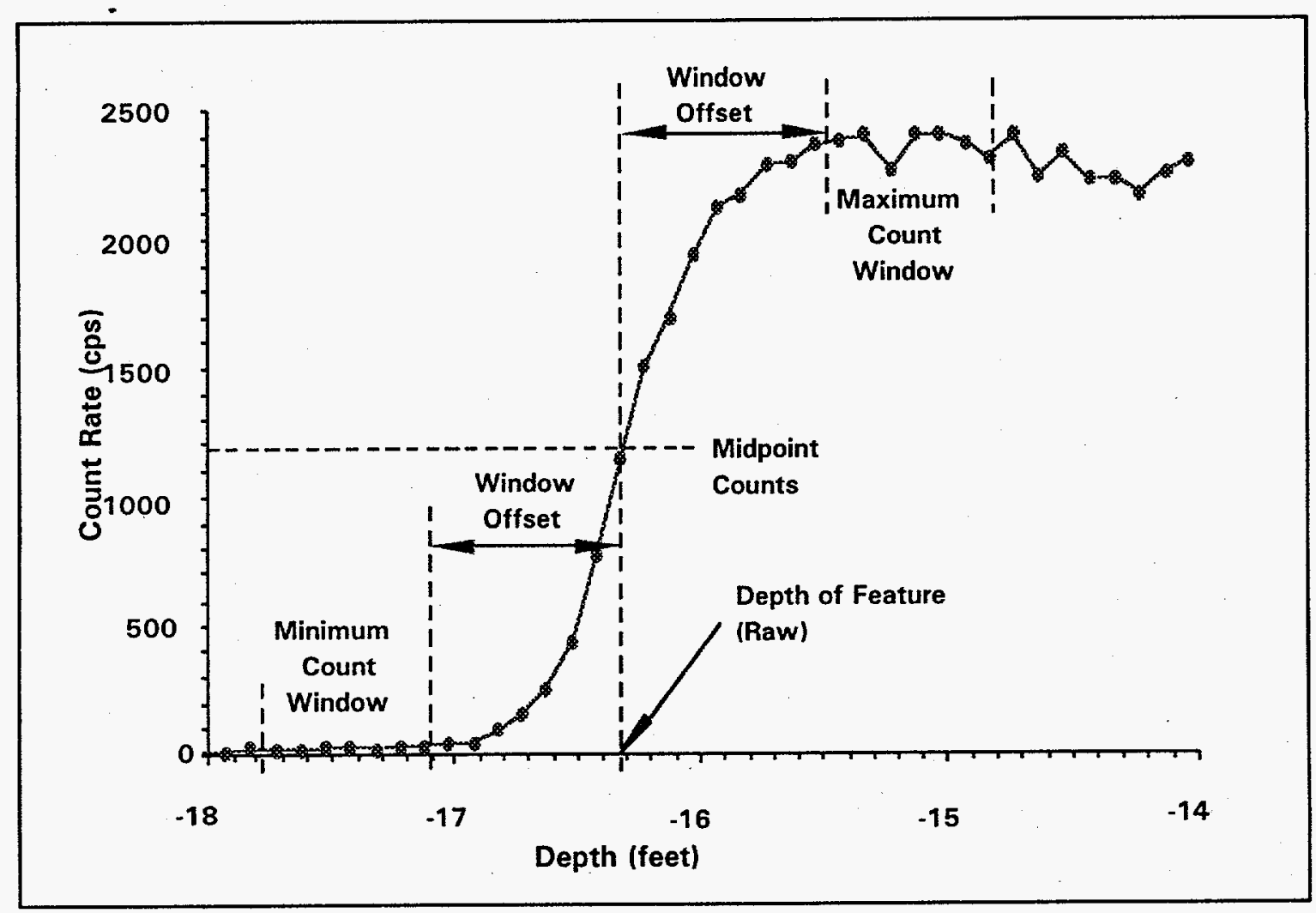

Figure 6 - The Derivative Method

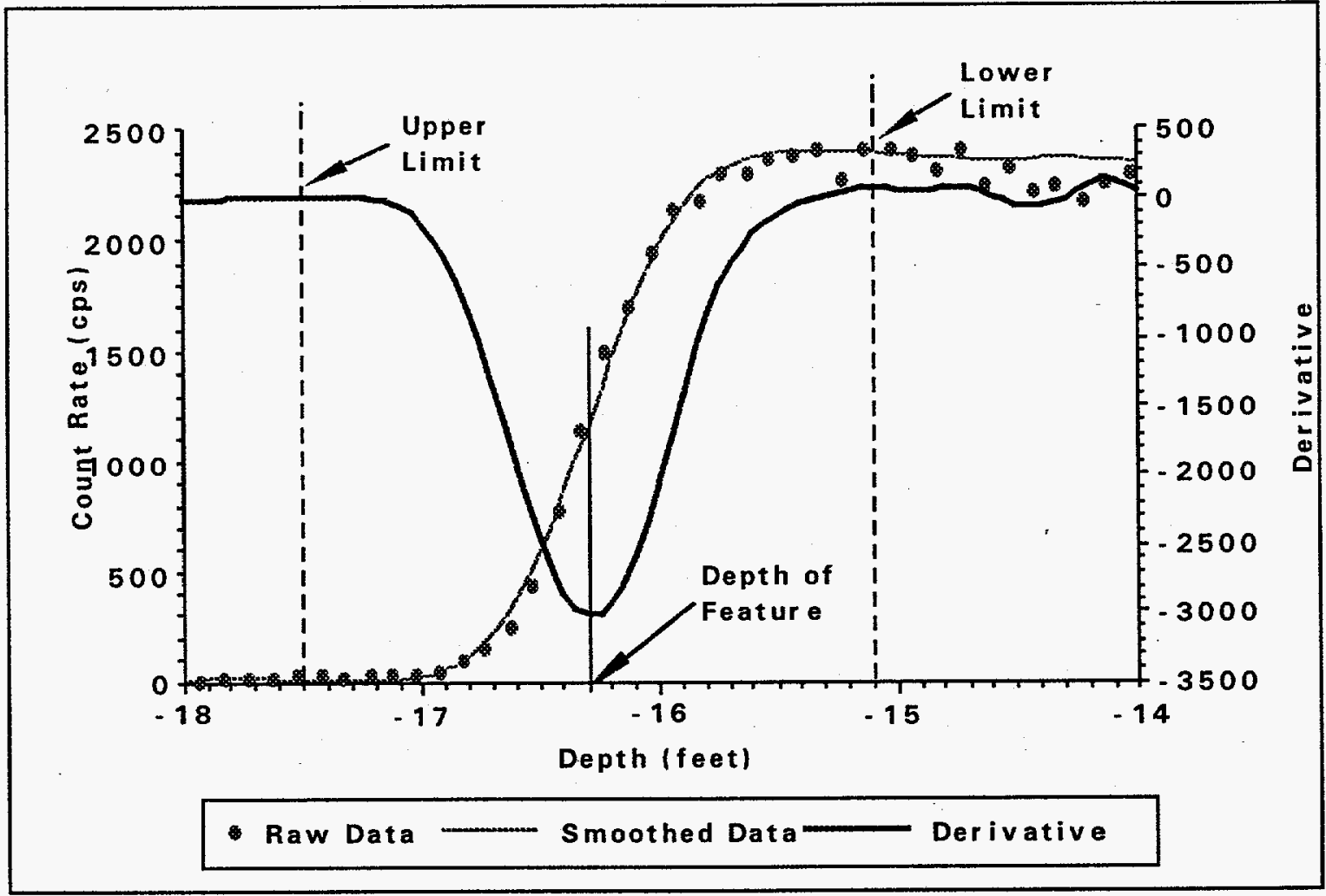


Figure 7 - The Sigmoid Method

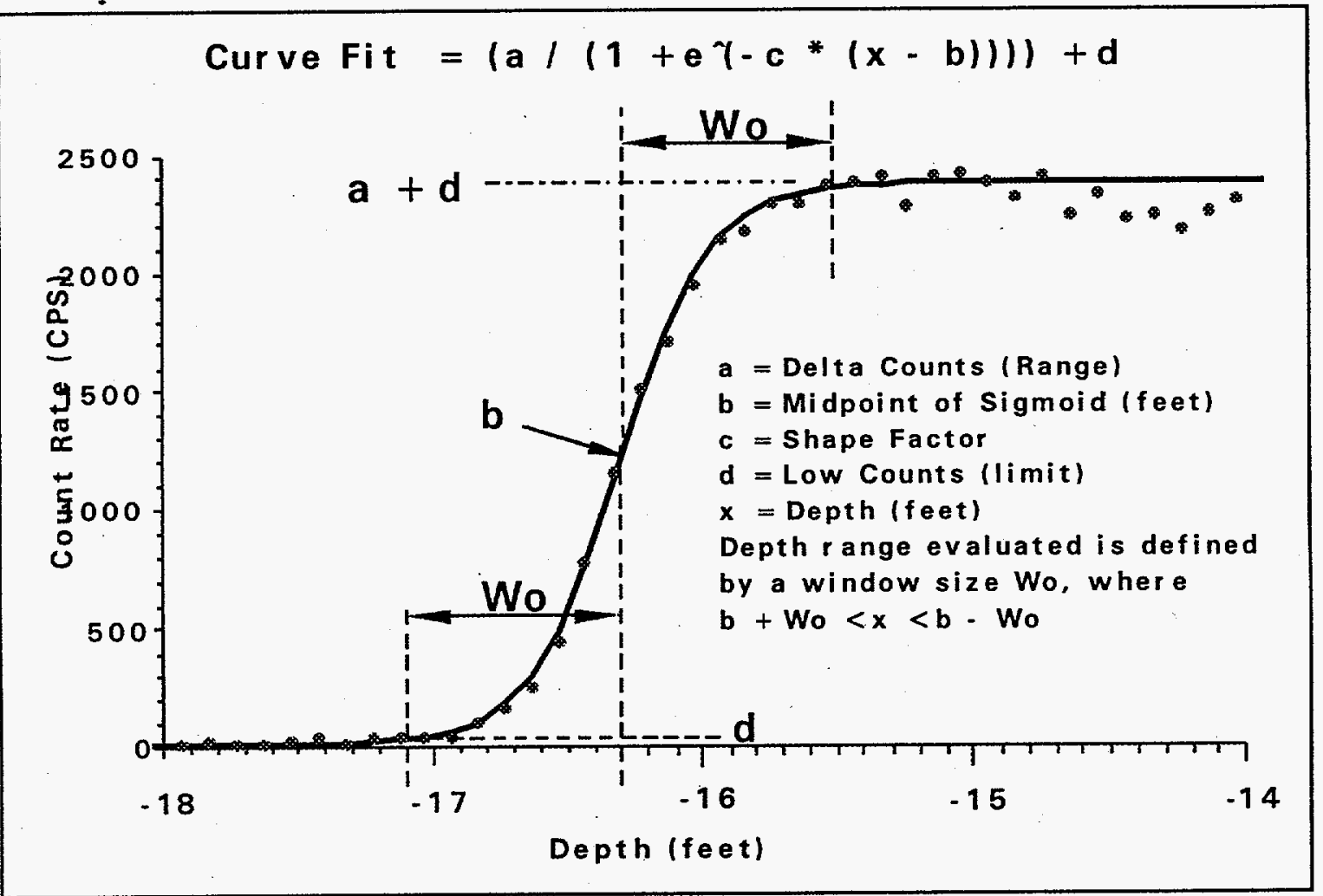

Figure 8 - Current SX102 ILL Interpretation

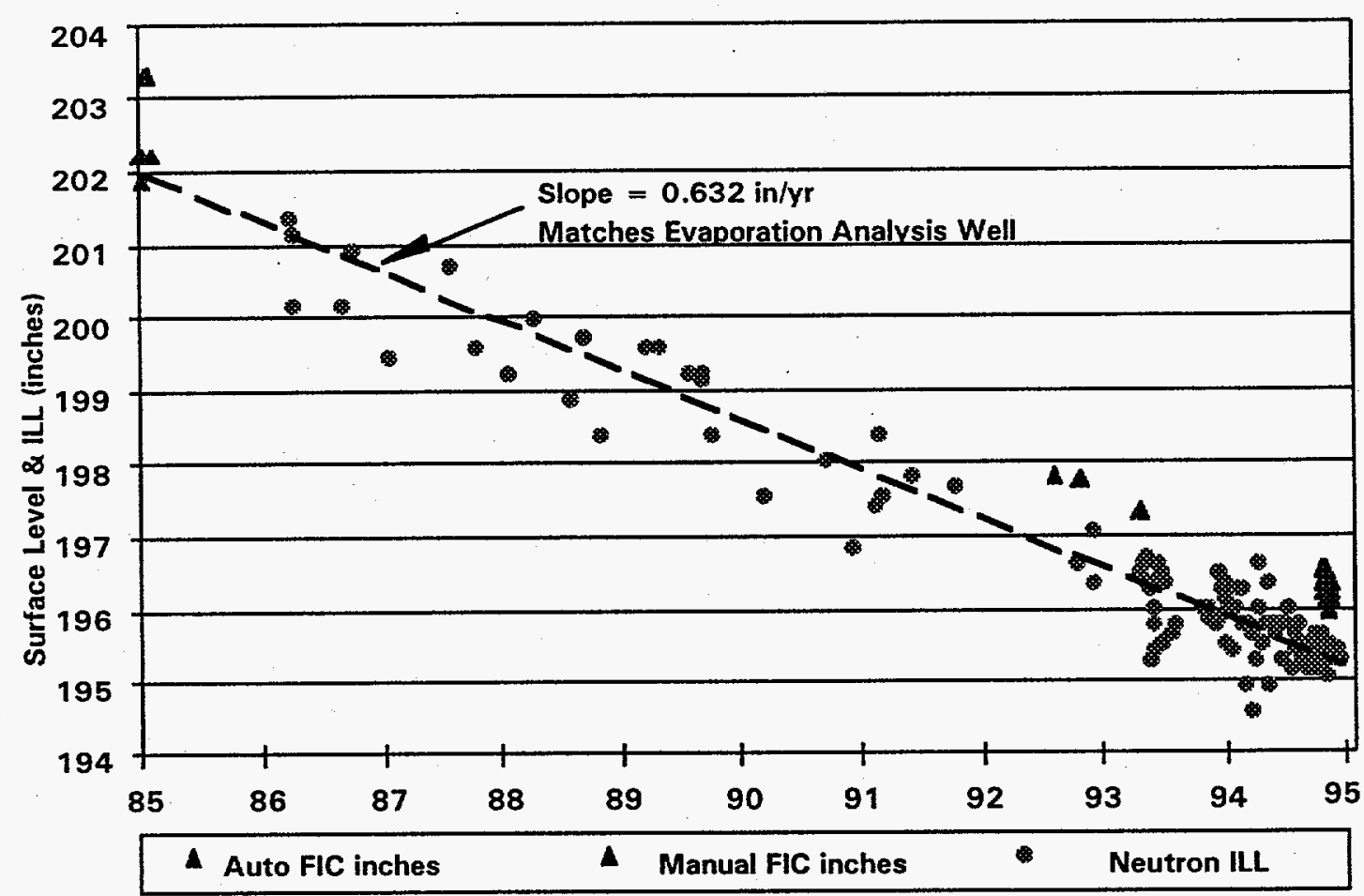

